\title{
Intent vs. Implementation-Food Allocation to Adult Males in WIC Households
}

\author{
Martin-Anderson $\mathrm{S}^{*}$
}

Assistant Professor of Health Services Administration, University of Missouri-Kansas City, Henry W. Bloch School of Management, Department of Public Affairs

${ }^{*}$ Corresponding author: Martin-Anderson S, 305E Bloch School, 5100 Rock hill Road Kansas City, Missouri 64110-2449, Tel: (816)235-2689, E-mail: martinandersons@umkc.edu

Citation: Martin-Anderson S (2014) Intent vs. Implementation-Food Allocation to Adult Males in WIC Households. J Nutr Health Sci 1(3): 307. doi: 10.15744/2393-9060.1.307

Received Date: July 09, 2014 Accepted Date: November 05, 2014 Published Date: November 07, 2014

\begin{abstract}
The intent of the Special Supplemental Food and Nutrition Program for Women, Infants and Children (WIC) program is found in its name-to increase the health status of a targeted group through supplemental food. Households often contain multiple members who are categorically ineligible, including older ineligible children and adult males. This paper focuses on potential spillover of benefits to adult males. Comparing multiple outcomes across treated and untreated households, the author finds evidence that consumption of certain WIC foods is higher among men in WIC households compared to the most appropriate comparison group: income eligible non-WIC participants. The author also finds evidence that this difference is attributable to food-sharing and not an income effect as there is no increase in the consumption of other, non-WIC foods. The increased consumption of cereal, milk and juice is only remarkable among married men in WIC households and not among single fathers. Additional evidence looking at the differences between married and single women's food consumption suggests that food is siphoned from the mother and not from the children; this finding supports the altruistic parent food allocation hypothesis. Most of the results are not robust to full controls, indicating that unobservable propensity to consume WIC foods may be driving entry into the program. If the findings of this study are a true representation of WIC implementation, policy makers should weigh whether this outcome is desirable in terms of the program mission.
\end{abstract}

Keywords: WIC Participation; Household Resource Allocation; Spillover Benefits; Nutrition; Poverty; Child Health

\section{Introduction}

The Special Supplemental Food and Nutrition Program for Women, Infants and Children (WIC) is a federal transfer program that provides vouchers for the purchase of approved foods. The program is funded and administered by the United States Department of Agriculture (USDA) and run at the local level by various agents, both public and private not-for-profit. In 2006, the year before this study period, federal expenditures for the WIC program totaled 6.2 billion dollars accounting for $11 \%$ of the USDA's 53 billion dollar food assistance budget. The 2006 program enrollment was approximately 8 million women, infants and children. The ultimate objective of the WIC program is to improve the health status of the country's nutritionally at-risk by increasing the consumption of healthy foods. Pregnant and nursing women, as well as their children age zero to five, are eligible pending income qualification and designation of nutritional "at-risk" status. Eligible women who enroll in the WIC program take paper or electronic vouchers to participating stores and purchase approved foods; unlike food stamps (SNAP), there is little or no flexibility in food purchases. By restricting purchases to WIC-approved foods, this policy avoids the potential for the negative behaviors associated with SNAP; SNAP participants consume more added sugars than income-eligible non-SNAP participants [1]. WICapproved foods during the study period included infant formula, infant cereal, milk, cheese, eggs, dried beans and juice [1]. Since the study period, bread, fresh fruit and vegetables have been added to the food basket [2]. The market value of the WIC food package is roughly 35 dollars per person for this paper's study period and averaged 90 dollars per WIC household [3].

This study focuses on potential spillover benefits to adult males residing in WIC households. WIC can affect male adult food consumption through two pathways: (1) income and (2) food sharing. Men may consume more food overall because of an income increase; they may also consume more food overall because they are consuming the particular WIC foods coming into the household. This study will explore these potential pathways.

The research domains in this study are:

1) Are WIC households consuming more WIC-approved foods than non-WIC households?

2) Are men in WIC households consuming more WIC-approved foods compared to men in non-WIC households?

3) Are the differences in food consumption attributable to an income or food-sharing effect (or both)?

4) Are married women in WIC households consuming less WIC-approved foods compared to women in single, unmarried households? 


\section{Background}

To understand the role of WIC in shaping food and nutrition decisions at the household level, one must recognize the complicated interplay of food policy and individual decision-making. WIC was designed with a specific intent that may or may not conflict with the intent of the household members. WIC could have effects on the nutritional adequacy of household food, the risk of food insecurity and the risk of income security - the gravity of this effect is modified by the behavior of its clients and, potentially, their family members.

\section{The Administration of WIC}

An extant literature in public administration concerns the dissonance between the intent and implementation of a program [2]. If WIC works as intended, all of the nutritional benefits awarded to the eligible would be consumed by the eligible. Household dynamics, in reality, likely spread WIC benefits throughout the family. It is argued that WIC has a bottom-up power dynamicthat even though the program is fully federally funded the power is concentrated on the front-line [3]. WIC staff has the ultimate authority to disperse benefits to whom they deem "nutritionally at risk"; there is little consensus on what this construct means. WIC is a good example of a policy designed around a socially constructed group [4]: nutritionally at-risk women, infants and children. Because the main point of entry into the program is a poorly defined construction, WIC runs the risk of both inefficiency and inequality in implementation.

\section{WIC and Household Food Security}

The literature on WIC suggests a protective effect against food insecurity for participating children, though the strength of this association is debatable. Physicians examining preschool children found improved health status among WIC participants [5], but acknowledge the difficulties of establishing causation. Kreider, Pepper and Roy [6] employ methods to more rigorously reduce endogeneity bias - their results estimate a 5.5\% reduction in childhood food insecurity and a $1.5 \%$ reduction in very low food insecurity.

A common assumption addressed in this study is the belief that WIC households consume more WIC approved foods than non-WIC households, and that this consumption of healthier alternatives drives health outcomes. Researchers in the Food and Nutrition Service arm of the USDA, in examining the food consumption patterns of WIC children-the largest segment of the WIC population-found a slightly improved diet quality within this group [7]. Sugar intake was lower among WIC children, compared to income-ineligible non-WIC children, likely due to substitution of WIC juices in place of higher-sugar sodas and punch drinks. There were no detectable differences in sugar intake between children on WIC and their non-WIC, income-eligible counterparts. An earlier study [8] found that children in WIC households, whether direct participants or not, consumed more of certain WIC foods than children in non-WIC households (whether income-eligible or not). This study found increased calorie intake from WIC foods, but not significant differences in calorie intake overall. In 2007, researchers employing Bayesian econometrics found that WIC families harbor unobserved propensities to consume certain nutrients, and that this propensity accounts for previous findings of increased intakes [9]. Families may be selecting into WIC based on pre-existing preferences for WIC approved foods. Ishdori and colleagues found this possibility most likely for milk and cheese.

\section{Past Research on Spillover}

This study builds on work by Ver Ploeg [10], Robinson [11] and others. Both Ver Ploeg and Robinson examined spillover benefits to older ineligible children of WIC households. Both studies found improved health and nutritional outcomes among ineligible children residing in WIC households. Using scores on the Healthy Eating Index (HEI) as an outcome variable, both researchers found improved health outcomes for some ineligible children living in WIC households. In Robinson's paper, this association was only remarkable for older male children. Earlier work on the spillover phenomenon [12,13] posits that household-level health benefits are partially a function of nutrition education and clinic visits.

Woodward and Ribar [14] include WIC analysis as a part of a broader research design looking at all supplemental food assistance programs. They find that WIC is associated with greater consumption of milk and cereal.

\section{Theories of Food Allocation}

Research on intra-household food allocation is a direct descendent of Gary Becker's [15] work on household production functions. According to this field of inquiry, households are both producers and consumers-they constantly trade-off time, labor and leisure and will allocate goods to optimize production. In this way, WIC is a type of unearned income flowing into the home; the benefits in a rational household will be dispersed as a function of household preferences regardless of program intent. The benefits will be allotted to family members with respect to return on investment. The question then is whether the return on investment is higher for the adult male or for the women and children targeted by WIC. As Duncan Thomas clarifies, according to Becker's model, "as long as the household remains intact, it may be treated as if it acts as a single individual; put another way, all resources are pooled and then reallocated according to some common rule" [16]. If WIC program intent is the common rule in the household, we expect to see no evidence of spillover benefits to the men in the household. 
Much work has been done building on the household production function as a foundation for food allocation models; the results vary. Most of the work on intra-household allocation of food occurs in the developing world where food resources are the scarcest. Seminal work by Behrman [17] finds evidence suggesting parents do allocate food according to maximization of labor returns and are, on average, pro- male child. Behrman goes on to conclude that this pure investment model is most powerful during the "lean" season when resources are most scarce. Behrman also contends that, compared to research in the United States, those in developing countries are less likely to exhibit "inequality aversion"-the act of compensating for child deficiencies with an increased allocation of resources. According to other research [18], the pro-male bias in allocation is also age specific. Adult males are the most preferred, followed by older male children, younger male children and then the women in the household in that order. If pro-male bias exists in this study-U.S residents of varying races, genders, household size and classes-one would expect a noticeable spillover of benefits from the eligible to the ineligible.

Models in the extant literature assume that all foods provide equal utility, or that preferences among foods do not vary by other characteristics. If WIC foods are systematically preferred by children, or by men, then a transfer of WIC foods from the young eligible to the older ineligible does not contradict the "return on investment" model. Household members could be rationally maximizing the utility of each member based on individual preferences, ignoring program intent. Spillover does not mean that fathers are "stealing" food from their children: the level of overall food consumption could be constant while the proportion of total consumption made up of WIC foods would be larger for those members who prefer them more. There is little literature on systematic food preferences of adult males and how they differ from adult females and children. A 2003 study [19] and colleagues explored the definition of "comfort food" and how it differed by gender. They found significant associations between savory foods, such as steak, casseroles and soups, and male gender. Conversely, the females on average preferred sweeter foods such as chocolate and ice cream. An older study [20] found the highest correlation among family members between women and children: both groups tended to prefer sweeter foods in addition to dairy products. This correlation inserts an interesting dynamic into this study-if preferences are more common between women and children, and WIC serves that population, certain WIC approved foods would be more commonly consumed. These foods would likely be breakfast cereal, juice and peanut butter.

\section{The Household as a Rational Consumer}

Every household spends a certain amount of money on groceries-the presence of free food in the household could bring food levels to optimal, freeing up income for other kinds of groceries or other household expenses. This assumes that preferences for food quantity and type are fixed and will not shift as a result of the program. The presence of free food in the household could also lead to overconsumption. If households are rational, we would see no difference in WIC and non WIC households. If we see differences between them, it means that WIC is altering preferences, leading to overconsumption. Studies of the SNAP program suggest that households will consume more food than otherwise when using in-kind transfers instead of household cash income [21]. In the absence of a true counterfactual household, this study attempts to create a counterfactual family whose consumption patterns are interpreted as a WIC family's patterns in the absence of treatment. This is an assumption obviously fraught with issues, the implications of which are discussed in the concluding section of the paper.

If a family receives free food, we expect cash spending on food to decline assuming rationality, fixed preferences and policy efficiency. For example, if two families each optimize their pre-WIC spending at 500 per month, the post-WIC difference between the two groups should be the WIC market value. If one family now gets 90 dollars' worth of groceries, post-WIC spending would be 410 dollars of their own money, freeing up money for other expenses. The money could also be freed up for other foods, meaning that there would be no detectable difference in grocery spending between the households. Similar grocery spending could indicate inefficiency in the WIC program structure if program benefits do not match beneficiary preferences and the nutrition education is not influencing preferences or behavior.

\section{Methods}

\section{Data and Eligibility}

Data were obtained from the 2007-2008 National Health and Nutrition Examination Study (NHANES). This wave of the NHANES was the last wave before the food package was expanded, making the simplicity of the study more desirable. It was also the most recent wave for which public use data was available. Individual respondents participated in interviews about themselves and their families. Only observations about the respondent were retained in my analysis sample; respondents also completed interviews about their family members but the family ID variable that links those responses was eliminated from the NHANES. Most of the full sample ( 70\%) took a 4 hour medical exam and dietary analysis at a mobile examination center (MEC).

Analysis is restricted only to households who are income eligible based on the 2007-2008 income cutoffs for WIC and reported family size. Table 1 reports demographic characteristics for WIC households and income-eligible non-WIC households. Also excluded are households who reported WIC usage but currently had no children or pregnant women in the household. Singlewoman WIC households (i.e. single pregnant women) are also excluded. 
Observations are weighted by the full sample 2 year MEC exam weight.

\begin{tabular}{|c|c|c|}
\hline & $\begin{array}{c}\text { Respondents Residing in WIC } \\
\text { Households }\end{array}$ & $\begin{array}{c}\text { Respondents not Residing in } \\
\text { WIC Households }\end{array}$ \\
\hline Male & .52 & .55 \\
\hline $\begin{array}{c}\text { Single Parents (Unmarried, } \\
\text { Unpartnered) }\end{array}$ & .29 & .42 \\
\hline Race and Ethnicity & .32 & .17 \\
\hline Mexican-American & .12 & .10 \\
\hline Other Hispanic & .33 & .51 \\
\hline White, Non-Hispanic & .19 & .16 \\
\hline Black, Non-Hispanic & .04 & .06 \\
\hline Other Race or Ethnicity & 1.17 & .98 \\
\hline Mean Income to Poverty Ratio & 32.54 & 40.40 \\
\hline Mean Age & & .04 \\
\hline Education Level & .16 & .11 \\
\hline Less than 9th Grade & .31 & .23 \\
\hline 9-1 $1^{\text {th }}$ Grade & .26 & .31 \\
\hline High School Grad/GED & .22 & .31 \\
\hline Some College or AA Degree & .05 & \\
\hline College Graduate or Above & & \multicolumn{2}{|c|}{} \\
\hline & & \\
\hline
\end{tabular}

Table 1: Weighted Summary Statistics for all Income Eligible Households

\section{Outcomes}

The work of past scholars is combined to address both consumption of WIC-approved foods and potential health effects of the food consumption. The Healthy Eating Index (HEI) is not used as an outcome, since the WIC benefits and the HEI are built on similar dietary guidelines. The following list outlines the definition of each outcome variable:

Consumption of WIC-approved foods: Food diaries were coded by NHANES researchers for a 24 hour period. Each food entry code was grouped for this paper according to the WIC food package during the study period. Each food could only belong in one category; multiple category foods were excluded. The milk, juice, eggs, beans, peanut butter and cereal groups were deemed "WIC approved" and each respective group was treated as a separate outcome variable. A food item is marked " 1 ” if it is Category X and 0 if it is not. This variable is interpreted as the likelihood that the particular food item is Category X. Responses are weighted by the number of total food items in a day.

Consumption of non WIC foods: Food categories chosen for analysis included Meat (all meats excluding seafood) [4], Vegetables [5], Fruits, Soda, "Sweets" (including candy and sweet baked goods) and Alcohol.

Monthly Grocery Spending: Measured by respondent recall of the previous month. Weighted by household size.

Evidence of Food Insecurity: Respondents in the NHANES were asked multiple food security questions. A binary variable was constructed indicating incidence of food insecurity by assigning a " 1 " to respondents who answered that they "often" or "sometimes" worried they would run out of food or could not afford balanced meals or relayed worry about running out of food each month. Respondents only had to answer affirmatively to one of the measures in order to be measured as a " 1 " for the new variable.

Calories, Sugar and Protein Consumed: Calories, grams of sugar and grams of protein were imputed by NHANES staff based on the food diary entries of respondents.

\section{Independent Variables}

Multiple factors affect food consumption patterns beyond WIC participation. Some of these factors also predict entry into treatment. Even after limiting this research to those who are income-eligible for WIC, the income gradient still predicts WIC status-low-income households are much more likely to be WIC households compared to higher-income households still under the cutoff point. Age also significantly predicts WIC; younger adults are more likely to take-up the program given eligibility. Hispanic ethnicity, lower educational attainment, larger household size, poor health status, high BMI, high food insecurity and a partnered or married marital status also positively correlate with WIC take-up. 
Food consumption is influenced by culture, availability of food, household size and budget constraints. Low-income households structurally, because of neighborhood built environment, have less access to healthy foods. They must also maximize a budget in a food system that incentivizes processed food production [22]. Because of the potential for confounding, these demographics are used as controls in the fully saturated model estimating the association between WIC and outcomes.

Treatment: Treatment is defined as having received household WIC benefits (either at the mother or child level) in the past 12 months. There is no way of distinguishing whether the family is currently receiving WIC benefits in the public use data set.

Model: Simple models of outcomes at the household level address research questions (1) and (2): whether outcomes differ by WIC status at the household level for the ineligible men within those households. Estimates are produced for both naïve and full-controls model. The full model includes a vector of demographic confounders predicting treatment and outcomes at both the individual level (race, ethnicity, age, and education) and household level (income and household size). All models include only income-eligible households by size for the same respondent gender.

Similar estimates are produced using non-WIC food consumption and grocery spending to address research question (3) increases in the consumption of other foods, or decreases in grocery spending, provide evidence of an income effect.

$$
\mathrm{C}_{\mathrm{xij}}=\beta 0_{\mathrm{i}}+\beta 1 \mathrm{~W} 1 \mathrm{IC} \mathrm{C}_{\mathrm{j}}+\delta_{\mathrm{i}}+\gamma_{\mathrm{i}}+\varepsilon_{\mathrm{ij}} \mathrm{V} \text { Income Eligible by Gender }
$$

The fully saturated model estimates the outcomes as a function of WIC treatment, Marital Status and an interaction term of the two.

$$
\mathrm{C}_{\mathrm{xij}}=\beta 0_{\mathrm{i}}+\beta 1 \mathrm{WIC}_{\mathrm{j}}+\beta 2 \mathrm{MARITAL}_{\mathrm{i}}+3 \beta \mathrm{WIC}^{*} \mathrm{MARITAL}_{\mathrm{ij}}+\delta_{\mathrm{i}}+\gamma_{\mathrm{i}}+\varepsilon_{\mathrm{ij}} \mathrm{V} \text { Income Eligible by Gender }
$$

The interaction term isolates the variation in food consumption (or other outcomes) attributable to the presence of WIC and presence of a spouse independent of the unique contribution of those variables separately. The interaction term model investigates not only whether men receive spillover benefits (research question 2), but from whom those benefits might be transferred (research question 4 ).

\section{Results}

Table 2 shows the difference in WIC food consumption by WIC participation; column 1 does not control for eligibility, while column 2 includes only income eligible non-WIC households. Respondents in WIC households consume significantly more cereal, milk and juice compared to non-WIC households after excluding the income-ineligible. The differences in the remaining food categories was insubstantial.

Large positive differences in the consumption of non-WIC foods would indicate an income effect-WIC could free up income to purchase other kinds of foods. There is no evidence of an income effect when measured in this way-WIC households do not consume significantly more or less meat, fruit and vegetables than non-WIC households.

Similar trends in household consumption are evident when analyzing men alone (Table 3), with two exceptions. Men in WIC households, compared to income-eligible men in non-WIC households, eat more beans and less peanut butter. Men also consume similar amounts of meat, fruit and vegetables, mirroring the results from table the household level analysis.

Female consumption patterns are reported by marital status, excluding the income-ineligible (Table 4). The differential patterns of married vs. unmarried women points to the relationship between male presence in a household and food allocation. WIC women with male partners in the household eat significantly less cheese and peanut butter and more juice. Among married WIC women we do not see the same patterns of cereal and milk consumption that we see in men. This implies that if household level differences in the consumption of these two WIC foods are evident, they are driven by the increased consumption of cereal among the men. Among unmarried WIC women, we do see an increase in milk consumption. There was no evidence of an income effect among married or unmarried women when measured by consumption of non-WIC foods.

Junk food consumption would be higher in WIC households if freed up income was transferred to the purchase of unhealthy goods. The only increase in consumption is among married women (Table 5); married WIC women drink significantly more soda than married non-WIC women. The direction of the relationship is negative in the other two groups, though the likelihood that the result occurs by chance in unmarried women or men of any marital status is high.

Grouping married and unmarried women and comparing them to men, Table 6 shows that WIC households consume significantly less protein and calories than non-WIC households. The magnitude of the effect is much larger among women, but the standard errors follow the same trajectory. The standardized effect sizes are roughly equivalent. There was no difference in BMI or Sugar intake among male or female respondents. 
Analysis indicated a negative correlation between WIC participation and grocery spending. WIC households, regardless of respondent gender, are more likely to be food insecure and less likely to be in good or excellent health. The relationship between WIC and grocery spending could indicate an income effect but, along with the other two variables, is likely a measure of negative selection into the program.

Lastly, Tables 7.1 and 7.2 present results from the fully saturated model of WIC participation and marital status for men and women separately. The independent effect of WIC participation on outcomes is no longer statistically different from random for men. None of the coefficients on the interaction term, comparing single men on WIC to married men not on WIC, are remarkable. There is evidence that single male parents are consuming less protein and far less calories than married male parents even after controlling for the confounders.

Among females, the fully saturated model leaves only one significant coefficient-consumption of juice. Further, the difference in milk consumption among single WIC participants vs. married non-WIC participants stays positive and significant, strengthening the findings from table 4. Male partners in a home may siphon this particular benefit from the mother, but not from their own children.

\begin{tabular}{|c|c|c|}
\hline & WIC vs. Non-WIC & $\begin{array}{c}\text { WIC vs. Non-WIC | } \\
\text { Income Eligibility }\end{array}$ \\
\hline Milk & $.023^{* * *}$ & \\
\hline Cheese & $-.002)$ & -.003 \\
& $\left(.003^{* *}\right.$ & $(.002)$ \\
\hline Beans & $.005^{* * *}$ & .002 \\
& $(.001)$ & $(.001)$ \\
\hline Eggs & -.0001 & -.001 \\
& $(.001)$ & $(.001)$ \\
\hline Cereal & $.006^{* * *}$ & $.004^{* *}$ \\
& $(.001)$ & $(.001)$ \\
\hline \multirow{2}{*}{ Juice } & $.014^{* * *}$ & $.013^{* * *}$ \\
& $(.002)$ & $(.002)$ \\
\hline Peanut Butter & $-.003^{*}$ & -.002 \\
& $(.001)$ & $(.001)$ \\
\hline
\end{tabular}

Table 2: Difference in WIC food consumption by WIC household status. Standard Errors in Parentheses

\begin{tabular}{|c|c|c|}
\hline & WIC vs. Non-WIC & $\begin{array}{c}\text { WIC vs. Non-WIC } \\
\text { Income Eligibility }\end{array}$ \\
\hline Milk & $\begin{array}{c}.021^{* * *} \\
(.003)\end{array}$ & $\begin{array}{c}.015^{* * *} \\
(.004)\end{array}$ \\
\hline Cheese & -.001 & -.002 \\
& $(.001)$ & $(.002)$ \\
\hline Beans & $.004^{* *}$ & $.003^{* *}$ \\
& $(.001)$ & $(.001)$ \\
\hline Eggs & -.0002 & -.001 \\
& $(.001)$ & $(.001)$ \\
\hline Cereal & $.006^{* * *}$ & $.004^{* *}$ \\
& $(.002)$ & $(.002)$ \\
\hline Juice & $.011^{* * *}$ & $\left(.007^{*}\right.$ \\
& $(.002)$ & $-.003)$ \\
\hline Peanut Butter & $-.002^{* *}$ & $(.001)$ \\
\hline
\end{tabular}

${ }^{*} \mathrm{p}<.05 ;{ }^{* *}=\mathrm{p}<.01 ;{ }^{* * *}=\mathrm{p}<.001$

Table 3: Difference in WIC food consumption by WIC household status. Men Only. Standard Errors in Parentheses 


\begin{tabular}{|c|c|c|}
\hline & $\begin{array}{c}\text { WIC vs. Non-WIC | } \\
\text { Income Eligibility } \\
\text { (Married) }\end{array}$ & $\begin{array}{c}\text { WIC vs. Non-WIC | } \\
\text { Income Eligibility } \\
\text { (Unmarried) }\end{array}$ \\
\hline Milk & $\begin{array}{c}.002 \\
(.005)\end{array}$ & $\begin{array}{c}.028^{* *} \\
(.010)\end{array}$ \\
\hline Cheese & $-.009^{* *}$ & -.007 \\
$(.003)$ & $(.005)$ \\
\hline Beans & .006 & .003 \\
\hline Eggs & $(.003)$ & $(.004)$ \\
\hline Cereal & -.001 & -.004 \\
$(.002)$ & $(.002)$ \\
\hline Juice & $(.002$ & .008 \\
& $(.003)$ & $.005)$ \\
\hline Peanut Butter & $.014^{* *}$ & $(.007)$ \\
\hline
\end{tabular}

${ }^{*} \mathrm{p}<.05 ;{ }^{* *}=\mathrm{p}<.01 ;{ }^{* * *}=\mathrm{p}<.001$

Table 4: Difference in WIC food consumption by WIC household status. Women Only. Standard Errors in Parentheses

\begin{tabular}{|c|c|c|c|}
\hline & $\begin{array}{c}\text { WIC vs. Non-WIC | } \\
\text { Income Eligibility } \\
\text { (Men) }\end{array}$ & $\begin{array}{c}\text { WIC vs. Non-WIC | } \\
\text { Income Eligibility } \\
\text { (Married Women) }\end{array}$ & $\begin{array}{c}\text { WIC vs. Non-WIC | } \\
\text { Income Eligibility } \\
\text { (Unmarried Women) }\end{array}$ \\
\hline Sweets: Baked Goods, & -.001 & -.004 & -.004 \\
Candy & $(.002)$ & $(.004)$ & $(.006)$ \\
\hline Soda & -.002 & $.030^{* *}$ & -.012 \\
$(.004)$ & $(.010)$ & $-0044)$ \\
\hline Alcohol & $-.002^{* *}$ & -.003 & $(.004)$ \\
\hline
\end{tabular}

${ }^{*} \mathrm{p}<.05 ;{ }^{* *}=\mathrm{p}<.01 ;{ }^{* * *}=\mathrm{p}<.001$

Table 5: Differences in "junk" food consumption by WIC household status and gender. Standard Errors in Parentheses

\begin{tabular}{|c|c|c|}
\hline & $\begin{array}{c}\text { WIC vs. Non-WIC | } \\
\text { Income Eligibility } \\
\text { (Men) }\end{array}$ & $\begin{array}{c}\text { WIC vs. Non-WIC | } \\
\text { Income Eligibility } \\
\text { (Women) }\end{array}$ \\
\hline Sugar (grams) & $2.31(4.76)$ & $-17.29(11.81)$ \\
\hline Protein (grams) & $-5.84^{* *}$ & $-12.13^{*}$ \\
\hline Calories & $(2.16)$ & $(5.99)$ \\
\hline BMI & $-102.49^{*}$ & $-355.30^{*}$ \\
& $(51.61)$ & $(158.03)$ \\
\hline & -3.13 & 9.53 \\
\hline
\end{tabular}

${ }^{*} \mathrm{p}<.05 ;{ }^{* *}=\mathrm{p}<.01 ;{ }^{* * *}=\mathrm{p}<.001$

Table 6: Differences in nutrient intake and BMI by WIC household status and gender. Standard Errors in Parentheses

\begin{tabular}{|c|c|c|c|c|c|c|}
\hline & Milk & Cereal & Juice & CaloriesConsumed & Sugar & Protein \\
\hline \multirow{2}{*}{ WIC } & -.004 & .003 & -.002 & -129.56 & -4.69 & -7.62 \\
& $(.007)$ & $(.003)$ & $(.004)$ & $(103.23)$ & $(9.93)$ & $(4.31)$ \\
\hline \multirow{2}{*}{ Single } & -.011 & -.004 & .003 & $-217.98^{*}$ & -15.98 & $-12.21^{* *}$ \\
& $(.006)$ & $(.003)$ & $(.004)$ & $(92.26)$ & $(8.64)$ & $(3.90)$ \\
\hline \multirow{2}{*}{ WIC $^{*}$ Single } & .013 & .001 & .001 & 237.98 & 19.07 & 9.46 \\
& $(.010)$ & $(.005)$ & $(.006)$ & $(151.59)$ & $(16.29)$ & $(5.77)$ \\
\hline
\end{tabular}

${ }^{*} \mathrm{p}<.05 ;{ }^{* *}=\mathrm{p}<.01 ;{ }^{* * *}=\mathrm{p}<.001$

Table 7.1: Differences in outcomes. Fully Saturated Model controlling for demographic confounders. Outcome variables selected from significant naïve models only. Income-Eligible male respondents with children. Standard Errors in Parentheses. 


\begin{tabular}{|c|c|c|c|c|c|c|}
\hline & Milk & Cereal & Juice & CaloriesConsumed & Sugar & Protein \\
\hline \multirow{2}{*}{ WIC } & .002 & .005 & $.013^{* *}$ & 167.89 & 23.48 & 5.51 \\
& $(.005)$ & $(.003)$ & $(.004)$ & $(288.98)$ & $(22.25)$ & $(11.48)$ \\
\hline \multirow{2}{*}{ Single } & .001 & .0002 & .004 & 22.02 & 23.00 & -9.41 \\
& $(.006)$ & $(.003)$ & $(.005)$ & $(350.44)$ & $(26.34)$ & $(12.64)$ \\
\hline \multirow{2}{*}{ WIC ${ }^{*}$ Single } & $.026^{*}$ & .006 & -.0003 & -502.79 & -50.51 & -12.73 \\
& $(.011)$ & $(.006)$ & $(.009)$ & $(418.08)$ & $(31.39)$ & $(16.09)$ \\
\hline
\end{tabular}

${ }^{*} \mathrm{p}<.05 ;{ }^{* *}=\mathrm{p}<.01 ;{ }^{* * *}=\mathrm{p}<.001$

Table 7.2: Differences in outcomes. Fully Saturated Model controlling for demographic confounders. Outcome variables selected from significant naïve models. Income-Eligible female respondents with children. Standard Errors in Parentheses.

\section{Discussion}

WIC Households are consuming more milk, cereal and juice than eligible non-WIC households. Why they are doing so, and why the men in the household have systematic differences but are not program beneficiaries, is a complicated question. If a non-WIC, income eligible family is an appropriate counterfactual, the increased consumption of certain WIC foods in WIC households could be an indication of overconsumption. WIC cereal, milk and juice should be replacing the goods they would have had to buy with their own income, freeing up money for other foods or household needs. Positive differences in food consumption could also be an indicator of under consumption in the non-WIC household. Significant differences come out of the analysis because WIC brings food levels up to optimal.

The absence of any systematic differences in non-WIC food consumption, as well as grocery spending, suggests that the market value of WIC is likely too small to have a discernible income effect. If WIC had an income effect, we would expect to see increased consumption of non-WIC foods. We would also expect a significant difference in grocery spending-the data supports neither. If WIC households are spending the same amount of money on groceries, essentially, as non-WIC households at similar income levels and consuming roughly the same amount of healthy foods than it is not a stretch to hypothesize that the freed up grocery income is going towards less-healthy food. However, the findings of this paper do not support that hypothesis. WIC families are not consuming more soda, sweets or alcohol than comparable non-WIC families.

Controlling for demographic predictors of WIC take-up renders the significance of the previous findings null. Evidence points to a latent preference for WIC foods which may be driving the decision to participate. The implication that male preferences are driving WIC take-up is interesting, and should be further explored. Previous studies of proclivity to use infant formula [23] indicate that the desirability of the benefits drives take-up. No studies have been done thus far expanding that line of research to the rest of the food basket. Further, previous studies on brand loyalty to infant formula after WIC participation should be applied to food preferences and their potential shaping by the WIC program.

The heart of all WIC research is whether it "works". The particular focus of this study was to investigate how the benefits WIC brings into the household are allocated, but a secondary focus is on this overarching question of WIC efficacy. There is no discernible difference in food consumption patterns of women in WIC and non-WIC households, controlling for eligibility and other confounders. There is also no substantial evidence of an income effect. Body mass index is not significantly different from equal between the two groups, even though WIC mothers are consuming less calories on average. Coupled with the evidence that children in WIC households are showing improvements (see review of the literature), it is likely that WIC participation benefits for the household are concentrated in child outcomes [6].

In 2000, Besharov and Germainis argued for a series of WIC policy reforms based on an extensive review of the evaluative literature. The authors argue that perpetuating the idea that WIC works stifles debate on how to make the program work better. From the paper: "Beyond modest reduction in anemia and modest increases in the intake of selected nutrients, there is little research evidence about the effectiveness of almost $90 \%$ of the funds expended under the WIC program" [24]. Further, the programmatic intent of WIC in the 1970's was to reduce incidence in malnutrition, and yet the implementation of the program has changed little over the life course of the policy, even though the more pressing concern of nutritional experts today is obesity and overweight. Hunger is absolutely still a concern, and to disregard the role of WIC in hunger prevention is ill-advised. But obesity in the US has skyrocketed since WIC's inception-it is a disease correlated with poverty. Besharov and Germainis contend that battling obesity-moving from the framework of "too little" food to "too much food" - should be an expressed intent of the program and future evaluations of WIC must take this outcome into consideration. Greater program flexibility, including lowering the income threshold, targeting benefits to those who need it most and improving the relevancy of the nutritional counseling sessions could also make WIC more effective. But until policymakers confront the poorly founded contention that WIC is a cost-effective, well designed program, there will be no impetus for change. 


\section{Conclusion}

This paper addressed the following four research questions:

1) Are WIC households consuming more WIC-approved foods than non-WIC households?

2) Are men in WIC households consuming more WIC-approved foods compared to men in non-WIC households?

3) Are the differences in consumption attributable to an income or food-sharing effect (or both)?

4) Are married women in WIC households consuming less WIC-approved foods compared to women in single, unmarried households?

The evidence from my study suggests the following:

1) WIC households are consuming significantly more milk, cereal and juice than similar non-WIC households. This is likely due to latent preferences for WIC foods driving entry into the program.

2) Men in WIC households follow similar consumption patterns of the household. Women do not follow these same patterns, indicating that male food preferences could be driving entry into the program.

3) There is little evidence to suggest an income effect. Consumption of non-WIC foods, both healthy and unhealthy, was close to equal between WIC and non-WIC households of both genders. Grocery spending was roughly 50 dollars less per month in WIC households, which could be evidence of an income effect but could also be evidence of negative selection into WIC. Further analysis is needed to disentangle these competing theories.

4) Married women are drinking less milk than single women in WIC households, suggesting that men in WIC households are consuming milk that would otherwise--if our assumptions about the counterfactual groups hold-go to the adult woman. There was no significant difference in any other food category.

As more sophisticated methods of controlling for selection bias are developed, researchers can start to piece together how much of the behavior in WIC households is attributable to unobservable characteristics and how much is attributable to program effects. Qualitative information on the food allocation and consumption practices of WIC households is needed to supplement the quantitative work; how constrained families maximize the well-being of every member of the family is a research question too big for just one approach

\section{References}

1. Wilde PE, McNamara PE, Ranney CK (2002) The effect on dietary quality of participation in the food stamp and WIC programs. United States Department of Agriculture. Eco Res Service: 33837.

2. Van Meter DS, Van Horn CE (1975) The policy implementation process a conceptual framework. Adm Soc 6: 445-88.

3. Hanks CA (2006) Community empowerment: A partnership approach to public health program implementation. Policy Polit Nurs Pract 7: 297-306.

4. Schneider A, Ingram H (1993) Social Construction of Target Populations: Implications for Politics and Policy. The Am Polit Sci Rev 87: 334-47.

5. Carlson A, Senauer B (2003) The impact of the Special Supplemental Nutrition Program for Women, Infants, and Children on child health. Ame J Agri Eco 85: 479-91.

6. Kreider B, Pepper JV, Roy M (2013) Identifying the Effect of WIC on Very Low Food Security among Infants and Children. University of Kentucky Center for Poverty Research.

7. Cole N, Fox MK (2008) Nutrient intake and diet quality of WIC participants and nonparticipants. Food and Nutrition Service.

8. Oliveira V, Chandran RV (2005) Children's consumption of WIC-approved foods. U.S. Department of Agriculture (USDA) Economic Research Service.

9. Ishdorj A, Jensen H, Tobias J (2008) Intra-household allocation and consumption of WIC-approved foods: A Bayesian approach. Adv Econometr 23: 157-82. 10. Ver Ploeg, Michele (2009) Do Benefits of U.S. Food Assistance Programs for Children Spillover to Older Children in the Same Household? J Family Econ Iss 30: 412-27.

11. Robinson C (2012) Younger Siblings Can Be Good for Your Health: An Examination of Spillover Benefits from the Supplemental Nutrition Program for Women, Infants, and Children (WIC). J Fam Econ Issu 34: 172-84.

12. Basiotis PP, LeBlanc CK, Kennedy ET (1998) Maintaining Nutrition Security and Diet Quality: The Role of the Food Stamp Program and WIC. Family Econ Nutr Rev 11: 4-16.

13. Bitler MP, Currie J (2005) Does WIC Work? The Effects of WIC on Pregnancy and Birth Outcomes. J Policy Anal Manage 24: 73-91.

14. Woodward JV, Ribar DC (2012) Is Individually-Targeted Food Assistance Shared among Family Members?. Food Nutr Sci 3: 747.

15. Becker GS (1965) A Theory of the Allocation of Time. Econ J 75: 493-517.

16. Duncan T (1990) Intra-Household Resource Allocation an Inferential Approach. J Human Res 25: 635-64.

17. Behrman JR (1992) Intra-household allocation of nutrients and gender effects: A survey of structural and reduced-form estimates. Nutri Poverty.

18. Senauer B, Garcia M, Jacinto E (1988) Determinants of the intrahousehold allocation of food in the rural Philippines. Ame J Agr Econ 70: $170-80$.

19. Wansink B, Cheney MM, Chan N (2003) Exploring comfort food preferences across age and gender. Physiol Behav 79: 739-47. 
20. Logue AW, Smith ME (1986) Predictors of food preferences in adult humans. Appetite 7: 109-25.

21. Ludwig DS, Blumenthal SJ, Willett WC (2012) Opportunities to reduce childhood hunger and obesity: Restructuring the supplemental nutrition assistance program (the food stamp program). JAMA, 308: 2567-8

22. Alston JM, Sumner DA, Vosti SA (2008) Farm subsidies and obesity in the United States: National evidence and international comparisons. Food Policy 33: 470-9.

23. Martin-Anderson S (2013) Prenatal attitudes and parity predict selection into a U.S. child health program: A short report. Soc Sci Med 95: 128-32.

24. Besharov DJ, Germanis P (2000) Evaluating WIC. Eval Rev 24: 123-90.

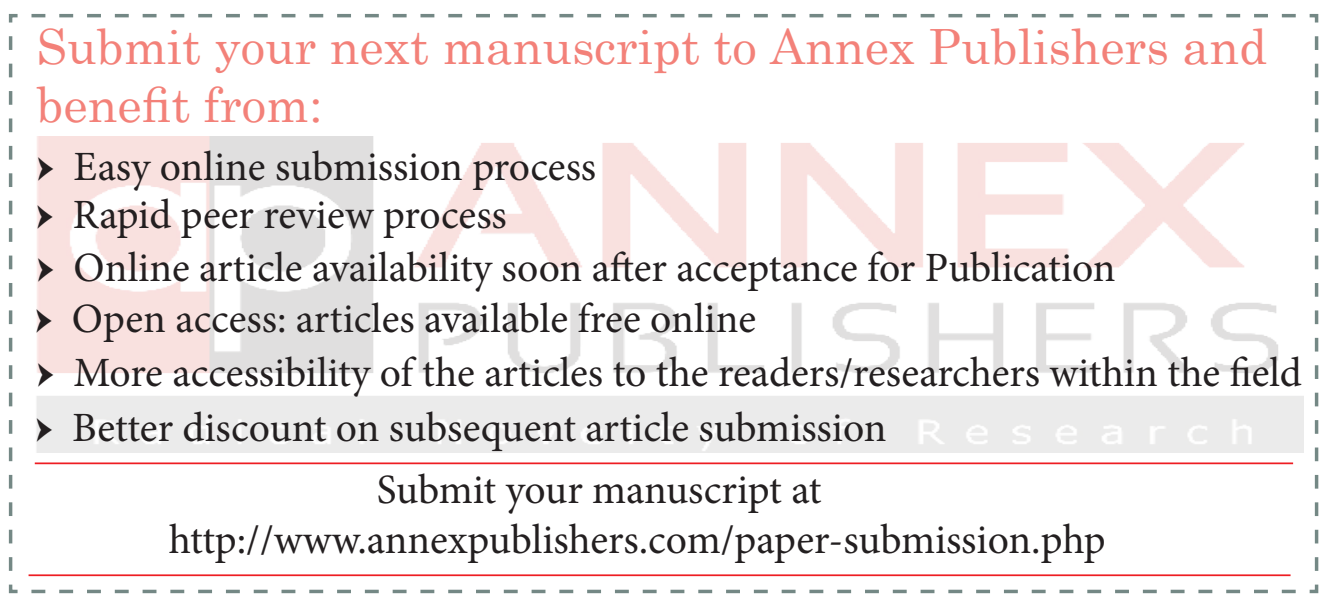

